\title{
Importância da pesquisa social em saúde
}

Prof. José Mouriño Mosquera

Prof. Claus Dieter Stobäus

As Ciências Sociais, como hoje as conhecemos, formaram-se principalmente num confronto com o avanço espetacular das ciências naturais e da tecnologia no final do século XVIII e no século XIV Digo isso asperamente, sabendo da complexidade que a afirmação dissimula. GIDDENS,1978 (p. 11)

Investigar a estruturação das práticas sociais é procurar explicar como as estruturas são constituídas pela ação, $e$ reciprocamente como a ação é constituida estruturalmente. GIDDENS.1978 (p. 169) 


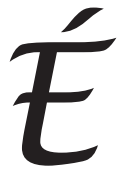

sabido que o ser humano tem estado sempre interessado em decifrar e conviver com seu meio ambiente e, especialmente, em entender a natureza dos

fenômenos que se lhe apresentam ante os seus sentidos. Obras belíssimas como "Uma história natural dos sentidos", de Diane Ackerman, o comprovam.

Os meios que the servem para alcançar estes fins podem classificar-se em três amplas categorias: experiência, raciocínio $e$ investigação. É importante alertar que, apesar de poderem ser analisadas por separado, estas categorias servem, quando integradas, para a busca de solução de complexos problemas que afetam a sua vida e o seu mundo em constante mutação.

Passamos a analisar estas três categorias, já que elas representam os níveis de conhecimento com os quais o ser humano lida e tenta desenvolver a sua existência.

Experiência: Emana de um certo número de fontes de informação ante a necessidade de resolução de um problema. A primeira fonte da experiência é a experiência pessoal, composta pelas vivências, habilidades, destrezas e interesses desenvolvidos com anterioridade. Já quando o problema é mais complexo e não faz parte do repertório das nossas habilidades, tendemos a recorrer a uma autoridade ou especialistas.

Este primeiro tipo de conhecimento é fundamental e serve como base de esclarecimento e pautas de vida. Pode ser chamado de "conhecimento do senso comum" e, hoje, se reconhece o seu valor ante a profundidade do cotidiano. Os autores mais inovadores (entre eles Habermas e Heller) têm salientado insistentemente que o significado profundo da cotidianidade não pode, de forma alguma, ser rejeitado.
Raciocínio: É a segunda categoria pela qual o ser humano tenta conhecer, de maneira mais aprofundada, o seu mundo, a sua sociedade e a si mesmo. O raciocínio pode ser estudado na tríplice dimensão: raciocínio dedutivo, raciocínio indutivo e o método combinado indutivo-dedutivo.

Como já se sabe, o raciocínio dedutivo se fundamenta no silogismo, que foi a grande contribuição de Aristóteles à lógica formal. $\mathrm{Na}$ sua forma mais simples o silogismo se compõe de uma premissa maior, fundamentada em uma proposição evidente e, numa premissa menor, que propicia uma instância particular e uma conclusão.

O silogismo foi um dos grandes recursos do intelecto humano até o Renascimento, quando começou a ser substituído pela vidência empírica. $O$ grande passo foi dado no século XVII, quando Francis Bacon deu ênfase sobre a ciência fundamentada na observação. Através das suas contribuições, propôs o todo de método de raciocínio indutivo por meio do qual o estudo de um número de casos individuais deveria levar a uma hipótese e, finalmente, a uma generalização.

A maior contribuição de Bacon foi ter orientado a atenção dos cientistas para a natureza em busca de soluções para os problemas do ser humano, exigindo a evidência empírica para sua verificação.

Por outro lado, estes dois enfoques se aproximaram e conseguiram/formar o indutivo-dedutivo, que consiste um movimento de trás para diante e no qual o pesquisador trabalha primeiro indutivamente, de observação a hipóteses, e depois dedutivamente, desde estas hipóteses até suas implicações com a finalidade de comprovar a sua validade, desde o ponto de vista de sua compatibilidade com o conhecimento aceito. Depois de revisá-las, quando for necessá- 
rio, se submetam estas hipóteses a provas posteriores, através da reunião de dados desenhados especificamente para comprovar sua validade empírica.

Esta dupla aproximação é a essência do método científico moderno e marca o último passo do progresso humano para a ciência empírica. Este é um caminho que leva o ser humano à compreensão mais profunda de um universo simbólico, rico, singular e, especialmente, desafiador, na concepção de autores como Geertz \& Clifford (1991).

A última categoria da qual nos iremos ocupar é a Investigação.

No mundo em que vivemos, a Investigação Científica tem um significado profundo, pois representa um dos instrumentais que mais tem contribuído para a ampliação do conhecimento humano e também para o aumento da perplexidade ante os desafios que a história e o cotidiano nos apresentam.

De forma geral a Investigação apresenta três características que a tornaram singular e, ao mesmo tempo, poderosa.

Primeira: A experiência lida com fatos produzidos ao acaso (ou casualmente), a Investigação é sistemática e controlada, fundamentando suas operações na induçãodedução.

Segunda: A Investigação é empírica, quer dizer que há a necessidade de validação em qualquer momento ou circunstância. Em outras palavras, a Investigação sempre gera a comprovação e sua conseqüente superação.

Terceira: A Investigação, pela sua natureza, é auto-corretora e, isto é, provavelmente, a função mais importante da Ciência, já que a correção de resultados, conceitos e procedimentos torna público o conhecimento e sua comprovação torna-se imperiosa.

Em síntese, a Investigação é uma combinação dialética de experiência e raciocínio e tem como missão a aproximação à verdade.

\section{REALIDADE SOCIAL: QUAL A CONCEPCÃO?}

Existe, na nossa época, um consenso que foi conseguido através de uma grande luta e conseqüente desgaste. Trata-se da dificuldade em possuir uma visão monolítica e única da realidade, por isto o consenso se dá na visão da multiplicidade'e da dinâmica simbólica dos processos cognitivos humanos. Portanto as ações humanas não são mecânicas ou simples repetições ao acaso.

É significativo o esforço para detectar quais são os pressupostos que regem a Investigação Científica e, por isto, passamos a analisá-los.

*Supostos de cunho ontológico: São os que dizem respeito à verdadeira natureza ou essência dos fenômenos que serão investigados. Por isto podemos questionar: É a realidade social externa ao indivíduo, ou é produto da consciência individual? Podemos sentir que estas questões nos levam ao debate nominalista-realista.

*Supostos de cunho epistemológico: São os que afirmam as verdadeiras bases do conhecimento (sua natureza, formas, como se podem adquirir e como comunicar a outros seres humanos), por isto alguns consideram a objetividade fundamental e outros admitem que a subjetividade é um compromisso com o humano. Se costuma conhecer os mais objetivos por positivistas e os mais subjetivos por antipositivistas.

* Supostos sobre a natureza humana e a relação entre pessoas e seu entorno: É evidente que, como o ser humano é tanto sujeito como objeto de seu estudo, as conseqüências para a Ciência Social são de extraordinária importância. Destes supostos emergem as imagens de ser humano que orientarão o trabalho científico e cujas conseqüências são fartamente conhecidas e discutidas na atualidade.
"No mundo

em que

vivemos, a

Investigação

Científica tem

um

significado

profundo,

pois

representa

um dos

instrumentais

que mais tem

contribuído

para a

ampliação do

conhecimento

humano e

também para

o aumento da

perplexidade

ante os

desafios que

a história e o

cotidiano nos

apresentam." 
Como é natural, os três tipos de supostos influenciam de forma decisiva sobre as metodologias e, obviamente, rompem com a famigerada neutralidade da ciência.

Assim, se temos uma visão do mundo social como o mundo natural (como se fosse uma realidade dura, externa e objetiva), então a Investigação se dirige para analisar as relações e regularidades entre fatores selecionados neste mundo. Conseqüentemente, se apresenta como predominantemente quantitativa. Esta caracterização de procedimentos e métodos, desenhados para descobrir leis gerais, pode denominar-se nomotética.

Porém, se a visão do mundo social acentua a importância da experiência subjetiva dos indivíduos na criação deste mundo, então a procura pela compreensão se enfoca sobre temas diferentes e suas possíveis e diversas aproximações. A inquietação principal é a interpretação, o método adota um aspecto qualitativo, tanto como quantitativo. A ênfase sobre o particular e individual é o que se denomina de ideográfico.

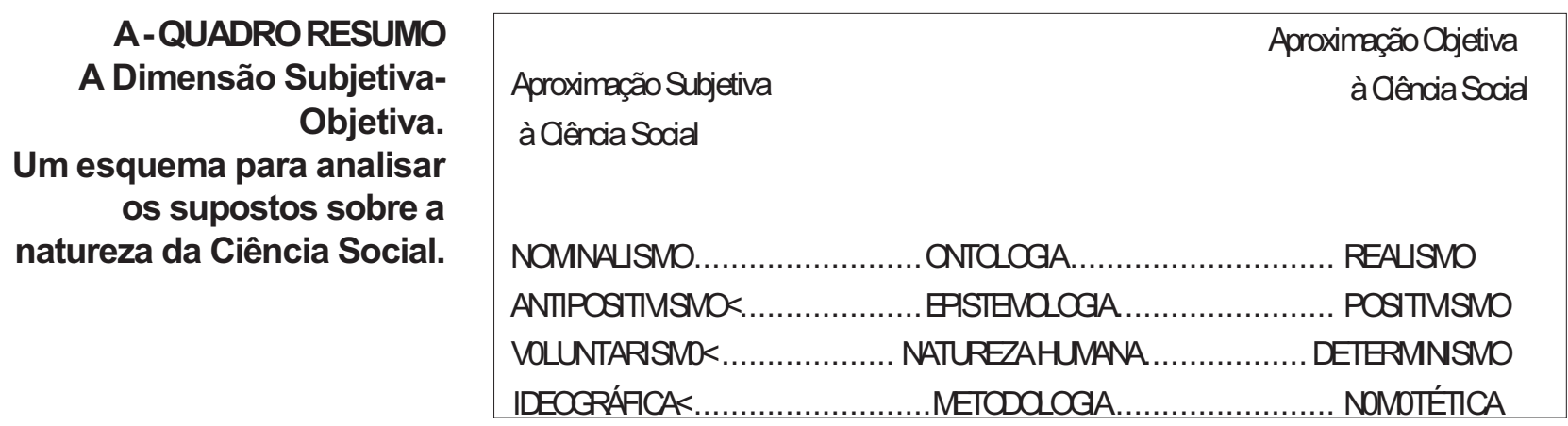

\begin{tabular}{|c|c|c|}
\hline $\begin{array}{l}\text { Dimensõesde } \\
\text { comperação }\end{array}$ & Objetivista & Subjetivista \\
\hline BaseFilosófica & $\begin{array}{l}\text { REAUSTA: Omndbexisteeé } \\
\text { cognosćvel œomoderealmenteé }\end{array}$ & $\begin{array}{r}\text { IDEAUSMD } \\
\text { Omindbexiste, mes as pessoeso } \\
\text { explicamdiferentemente. }\end{array}$ \\
\hline Opapel da Cê̂ncia Social & $\begin{array}{l}\text { Desodbrindbleis universais } \\
\text { clasociedace eda. } \\
\text { compartamerto humana. }\end{array}$ & $\begin{array}{r}\text { Desodarindbocmoas pessoes } \\
\text { interpretamomindo } \\
\text { emquevivem }\end{array}$ \\
\hline $\begin{array}{l}\text { Uridades Básicas da } \\
\text { Realidade Social }\end{array}$ & $\begin{array}{l}\text { Acoletividader sociedacte } \\
\text { auorganizaçōes. }\end{array}$ & $\begin{array}{r}\text { Individuos agindosozinhos } \\
\text { aureuridbs }\end{array}$ \\
\hline Métodos de entendimento & $\begin{array}{l}\text { Identificandbondições que permitam } \\
\text { existir a sociedade }\end{array}$ & $\begin{array}{l}\text { Interpretação dos } \\
\text { siginificados subjetivos que as } \\
\text { pesscas aplicamasuas açoes. }\end{array}$ \\
\hline Tearia & $\begin{array}{l}\text { Umedficioracional construídb por } \\
\text { cientistas peraexplicaro } \\
\text { compartamentohumana }\end{array}$ & $\begin{array}{r}\text { Corjuntode } \\
\text { significadbsqueas pessoas } \\
\text { usamparadar sentidbà suavida }\end{array}$ \\
\hline Investigação & $\begin{array}{l}\text { Validaçãoexperimental au } \\
\text { quase experimental datecria }\end{array}$ & 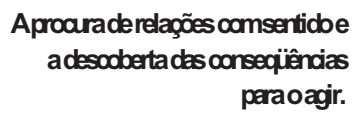 \\
\hline Metodblogja & $\begin{array}{l}\text { Abstraçãodarealicbde: } \\
\text { modelos mateméticos equatificação }\end{array}$ & $\begin{array}{l}\text { Representação darealicade } \\
\text { comfins de comparaçãa } \\
\text { Análise, linguageme significado. }\end{array}$ \\
\hline
\end{tabular}

B-QUADRO RESUMO Bases alternativas para interpretar a realidade social Concepções da realidade social 
Como podemos observar pelos quadro-resumo analisados, estamos ante duas vertentes ou formas de conhecimento que possibilitam diferentes leituras da realidade $\mathrm{e}$ nos levam a configurações sociais e culturais diferenciadas.

A visão objetivista tem como precursor mais insigne e atual o filósofo Auguste Comte, que conscientemente inventou uma nova ciência da sociedade. Pensou que era possível estabelecê-la em uma base positiva, junto com outras ciências que lhe serviriam como modelos. Portanto, os fenômenos sociais seriam vistos à luz das leis e teorias fisiológicas e pesquisados experimentalmente, tal como os fenômenos físicos.

Giddens et Clifford (1991) esclarecem a influência do moderno positivismo, dizendo que: 1) Os procedimentos metodológicos da ciência natural podem aplicar-se diretamente às Ciências Sociais; 2), $\mathrm{O}$ produto final das investigações realizadas pelo cientista social pode formular-se em termos paralelos aos da Ciência natural. Isto significa que a sua análise deve expressar-se em leis ou generalizações.

Evidentemente que o Positivismo alcançou êxitos inquestionáveis e inquietantes. Mas nos perguntamos: É suficiente, é completo para qualquer área do conhecimento e da ação humanos?

\section{PESQUISASOCIALESAÚDE: QUAL AREAĈ̃O?}

Sabemos muito bem da influência da ciência e metodologia positivistas nos diferentes campos do conhecimento humano e não negamos os seus extraordinários avanços e fantásticas realizações.

Mas, nestes momentos em que todo o saber e fazer estão sendo questionados, em que as epistemologias têm seu estatuto amplamente discutido, perguntamos: Qual o caminho a seguir?

Desde que Blake, o grande poeta inglês, reconheceu não ser o universo um mecanismo, senão um organismo vivo, as idéias de holismo, incompletude e dinâmica dialética têm sido enormemente revisitadas e apreciadas.

Nos finais deste nosso século XX, estamos convencidos (como pensava Kierkegaard) que a subjetividade e a concreção $d a$ verdade, unidas, constituem a verdadeira luz. A ciência atual não pode ser distante ou alheia, ela está comprometida com o sentido de humanidade e este significa o partilhar e o fazer intencional.

Por isso, em um enfoque mais crítico, poderíamos dizer que a Ciência Social $e ́$ entender a realidade social segundo a vêem pessoas diferentes, e demonstrar como suas visões conformam a ação que adotam dentro desta realidade.

Não é de causar espanto que, nestes momentos, tenham bastante relevância as dimensões: existencialista-fenomeno-lógica; interacionismo simbólico; análise hermenêutica; dinâmica dialética e as teorias críticas da sociedade, com suas dinâmicas de animação sócio-cultural e pesquisa-ação.

Estas novas possibilidades se espelham nos postulados:

(1) Os seres humanos agem na base de significados que têm sobre eles mesmos, sua sociedade e seu mundo.

(2) A atribuição de significados é um processo contínuo de dinâmicas simbólicas e reais. As idéias de Psicologia SócioHistórica nunca estiveram tão vivas e desafiadoras, bem como as contribuições de uma Psicologia de Cultura, harmonizando com as teorias do caos e a construção do holismo, nunca foram tão relevantes e oportunas.

(3) $\mathrm{O}$ processo de atribuição de significados tem valor porque é feito em um contexto social. Cada pessoa desenha a sua ação porque é inevitável a subjetividade do outro, em outras palavras só é possível o pessoal porque nos dirigimos à construção dinâmica e solidária de um social.
"É evidente que 0 Positivismo alcançou êxitos inquestionáveis e inquietantes. Mas nos perguntamos: é suficiente completo para qualquer área do conhecimento e ação humanos?" 
Em um universo que assim se apresenta, é básico perguntar qual o sentido da Saúde e a sua relação com a Pesquisa Social. Evidentemente que se trata de uma temática fascinante e ineludível. Na medida em que as ciências da saúde avançam, sua ontologia, sua epistemologia, sua concepção de natureza humana e sua metodologia são fortemente questionadas e revisadas.

Obviamente que a Saúde, tal como o ser humano, são de difícil definição e determinação. As tendências mais desafiadoras nos levam a concluir mais pela sua compreensão do que pela sua generalização. Saúde, como possível entendimento de equilíbrio-instável, em um mundo de rápidas e imprevisíveis mudanças, é algo que deve de emanar da abertura, da consciência do pessoal e da dinâmica do social.

A relação com Ciência Social é inquestionável e dialética, entretanto depende dos níveis de compreensão científica e do sentido do problema. Cremos não ser possível mais, inocentemente, atribuir valor mágico ao Método Científico, ele não tem este poder.

A ciência vale na medida em que tem valor o ser humano e é preciso resgatar esta relação ética, sem ela a Pesquisa Social se torna um mero instrumento sem sentido.

Ao encerrarmos este trabalho, acreditamos nas palavras de Mileva Maric a Albert Einstein

" Não creio que a estrutura do crânio humano deva ser culpada pela incapacidade do homem de entender o conceito de infinito. Poderia certamente compreendê-lo se, na juventude, enquanto desenvolve seu senso de percepção, fosse permitido a ele aventurar-se pelo universo, ao invés de ficar aprisionado à Terra ou, pior ainda, confinado dentro de quatro paredes num lugar provinciano."

\section{RERNASBEYORÁACAS}

ACKERMAN, Diane. Uma história natural dos sentidos Rio de Janeiro, Bertrand, 1992.

COHEN, Louis \& MANION, Lawrence. Métodos de investigación educativa. Madrid, La Muralla, 1990.

GEERTZ, C. \& CLIFFORD, J. El surgimiento de Ia antropologia posmoderna. México, Gedisa, 1991.

GIDDENS, A. Novas regras do método sociológico. Rio de Janeiro, Zahar, 1978.

KRIPPENDORFF, Klaus. Metodologia de análises de contenido. Barcelona, Paidós, 1990.

MOSQUERA, JUAN J. M. \& STOBAUS, Claus D. Educação para a saúde? Porto Alegre, D.C. Luzzato, 1984.

NUNES, Everardo Duarte (org.). Juan César Garcia. Pensamento Social em Saúde na América Latina. São Paulo, Cortez, 1989.

PÉREZ SERRANO, Maria Glória. Investigación-acción. Aplicaciones al campo social y educativo. Madrid, Dykinson, 1990.

PRINI, Pietro. História delExistencialismo. Barcelona, Herder, 1992.

POURTOIS, Jean-Pierre \& DESMET, Huguette. Epistemologia e instrumentación en ciências humanas. Barcelona, Herder, 1992.

RENN, Jürgen \& SCHULMANN, Robert (org.). Albert Einstein, Mileva Maric- Cartas de amor. Campinas, Papirus, 1992.

RUIZ OLABUÉNAGA, José Ignácio \& ISPIZUA, Maria Antonia. La descodificación de la vida. Métodos de investigación cualitativa. Bilbao, Universidade Deusto, 1989.

VYGOTSKY, L.S. Obras escogidas. I. Madrid, Visor, 1991.

Historia dei desarrollo de las funciones psíquicas superiores. La Habana, Cientifico-Tecnica, 1987.

\section{UNIERNOS}

Ciência social, pesquisa social, saúde.

Prof. José Mouríño Mosquera

Prof. Titular PUCRS e UFRGS

Prof. Claus Dieter Stobäus

Prof. Adjunto PUCRS e UFRGS 